\title{
ASIAN JOURNAL OF MEDICAL SCIENCES
}

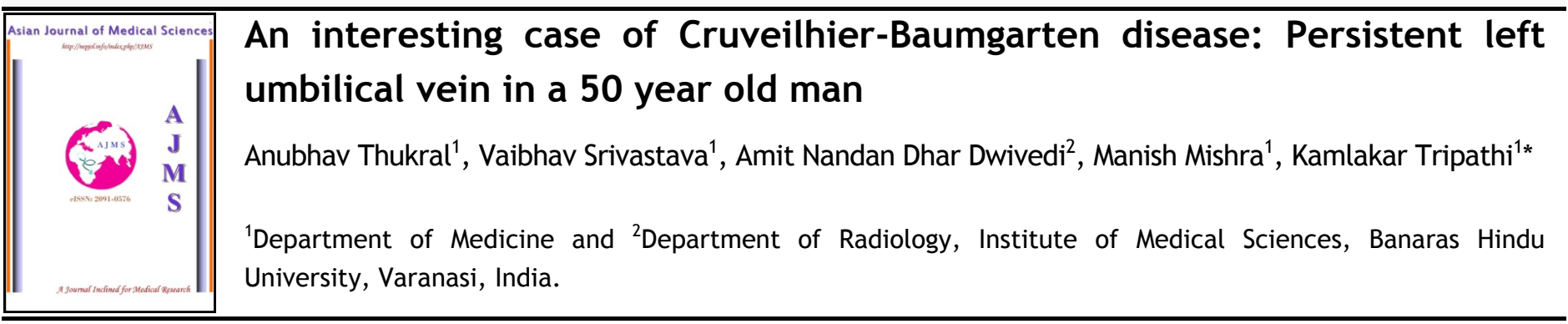

Abstract

A middle aged man of 50 years presented with features of portal hypertension without any features of liver decompensation or cirrhosis, found to have abnormal flow pattern in peri-umbilical vein, confirmed by Doppler to have a patent left umbilical vein. This represents a very treatable cause of portal hypertension as ligation of vein may result in complete reversal of disease process. The case also outlines importance of routine general examination like of seeing the direction of flow in periumbilical veins even in obvious cases of portal hypertension that helped us in detection of this case.

Key Words: Portal hypertension; Periumbilical vein

\section{Introduction}

\50 year old man, farmer by occupation, resident $\triangle 1$ of Bihar, U.P, India, came to our medicine OPD with chief complaints of 6-7 episodes of hematmesis in last one month. There was also history of black colored stools for the same duration. There was no history suggestive of bleeding from any other source, no history of yellow discoloration of eyes or urine in present or past; no history of acid peptic disorder in past, patient was not on any prior treatment. Patient was a non alcoholic, no history of blood transfusion, operative intervention, drug addiction or smoking.

On examination patient was pale, severe anemia was present; there was no icterus, clubbing, cyanosis, pedal edema and the patient was dehydrated. There were no stigmata's of chronic liver disease. Vitals were unstable with pulse rate $120 / \mathrm{min}$, blood pressure of $80 / 60 \mathrm{~mm}$ $\mathrm{Hg}$. Systemic examination revealed chest, cardiovascular and central nervous systems were within normal limits. Abdominal examination revealed a single prominent distended vein above the umbilicus (which the patient stated that was present since his birth) (Figure-1), on palpation it was found that flow was directed from

*Correspondence:

Dr. Kamlakar Tripathi, Professor, Department of Medicine, Institute of Medical Sciences, Banaras Hindu University Varanasi- 221005.

E-mail: kamlakar_tripathi@yahoo.co.in above downwards i.e. towards the umbilicus. Splenomegaly was present, $6 \mathrm{~cm}$ below the costal margin, there was no ascitis, no other organomegaly, and liver span was $14 \mathrm{~cm}$. Patient was immediately resuscitated with fluids and oxygen, and was shifted to endoscopy room. On upper GI endoscopy he was found to have 4 columns of grade 3 varices. Band ligation was done. Patient was then managed conservatively and transfused 3 units of blood components after which patient improved.

He was then subjected to routine blood chemistry including a prothrombin time which was normal. (Hb- 4g\%, total bilirubin- 1mg\%, AST- $32 \mathrm{IU}$, ALT $40 \mathrm{IU}$, Total protein- $6 \mathrm{~g} \%$, albumin $4 \mathrm{~g} \%$, creatinine- $1.2 \mathrm{mg} \%$, PTINR-1.03). Then he underwent a color Doppler and CT angiogram of hepato-portal splenic axis which showed a patent left umbilical vein opening into portal vein which was dilated (Fig-2), there were dilated collaterals, splenomegaly, but liver echo texture was essentially normal. Liver biopsy confirmed normal hepatic architecture.

\section{Discussion}

In this case we have found a man who presents with features of portal hypertension without any features of chronic liver disease (CLD) , he has no risk factors or stigmatas for CLD, no ascitis. 

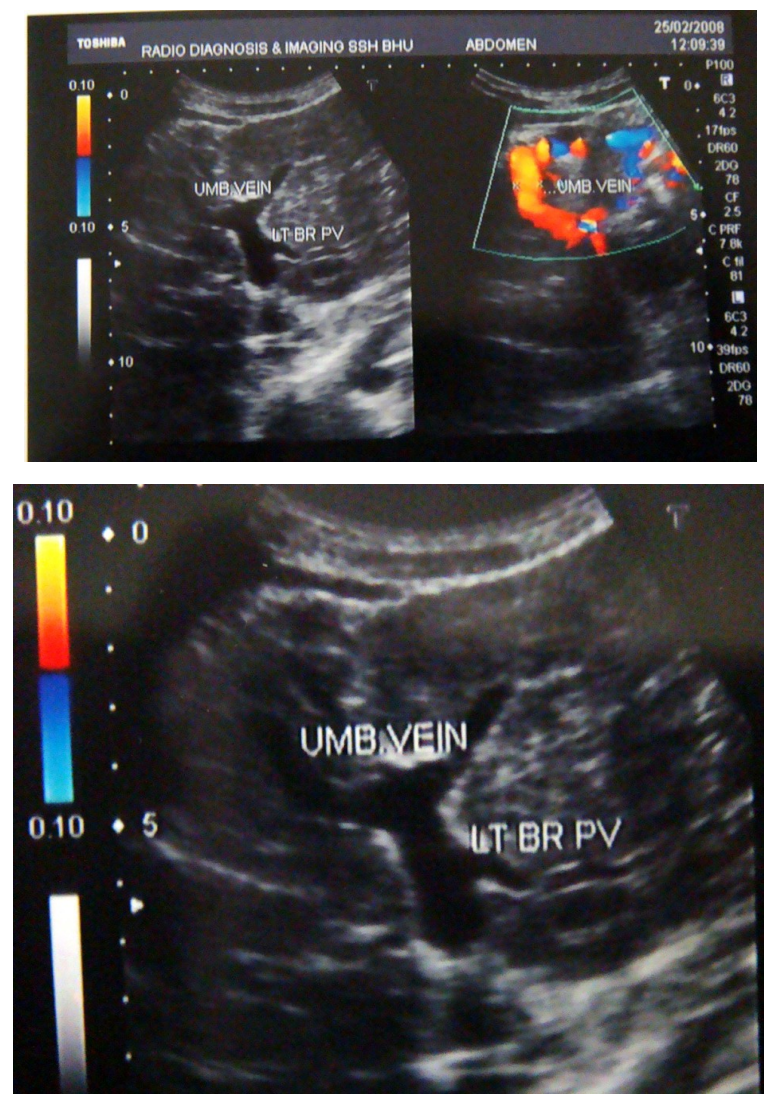

Figure-1: Color Doppler showing persistent left umbilical vein opening into left branch of portal Vein

His liver span is normal, his blood chemistry shows normal liver function tests, normal serum albumin, liver biopsy shows normal echo-texture. The only abnormal finding is a flow in supra-umbilical vein directed towards the umbilicus. This vein was present in the patient since birth. Normally in portal hypertension the flow is away from the umbilicus. This indicated us to go for a color Doppler and CT angiogram which ultimately led to the diagnosis of Cruveilhier-Baumgarten disease. Portal hypertension without ascites caused by patency of the umbilical or paraumbilical veins - with orifice directly into the portal vein - and the resultant collateral circulation resulting in local hyperdynamic circulation. It is associated with prominent periumbilical veins and splenomegaly. An auscultatory sound may be heard in the venous collaterals of the abdominal wall.

According to some gastroenterologists, CruveilhierBaumgarten disease and Cruveilhier-Baumgarten syndrome are not the same entity. Cruveilhier-Baumgarten disease, the disease caused by the umbilical vein remaining open after birth, with all the misery this causes in the portal vein system.

Cruveilhier-Baumgarten syndrome, the condition acquired when the umbilical vein is reopened because of increased pressure on the portal vein system in liver cirrhosis. $^{1-3}$

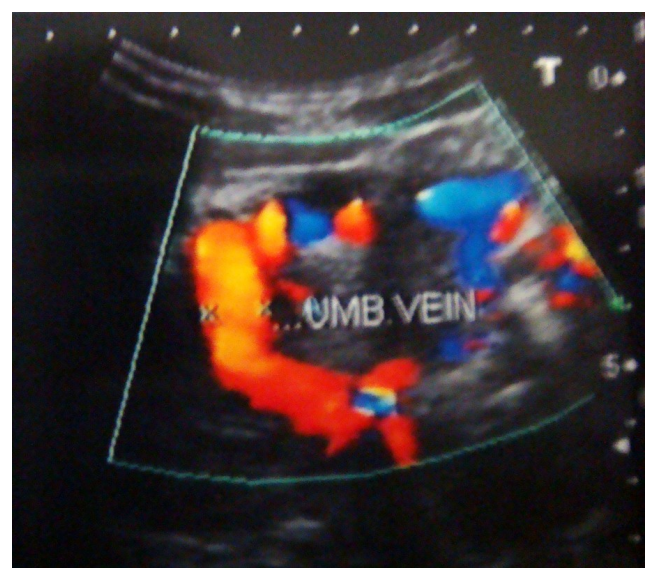

Figure-2: Color Doppler showing dilated and increased caliber of umbilical vein.

Only a few cases of this entity have been described since its initial description. ${ }^{4,5}$ Attempts to treat this entity have included surgical ligation of anomalous vein and liver transplantation to mention a few. ${ }^{6}$ The patient was treated for his hematemesis and managed conservatively. The patient improved and discharged after a brief hospital stay.

\section{References}

1. Cruveilhier J. Maladie des veines. In: Anatomie pathologique du corps humain. Traité d'anatomie pathologique générale 1852; 2:16.

2. Wertheimer E. Recherches sur la veine ombilicale. Journal de l'anatomie et de la physiologie normales et pathologiques de l'homme et des animaux, 1886; 22:1-17.

3. von Baumgarten P. Über vollständiges Offenbleiben der Vena umbilicalis; zugleich ein Beitrag zur Frage des Morbus Banti. Page 6; Baumgarten, Arbeiten, 1908, Arb Geb Path Anat Inst Tübingen, Leipzig 1907; 6:93-110.

4. Steinberg J S, Galambos J T. Cruveilhier-Baumgarten (C-B) Disease: an experiment of Nature. Am J Med 1967; 43: 284-8. doi:10.1016/0002-9343(67)90170-2

5. Bisseru B, Patel J S. Cruveilhier-Baumgarten (C-B) Disease. Gut 1989;30:136-7. doi:10.1136/ gut.30.1.136 PMid:2920918 PMCid:1378244

6. Aucejo F, Ibrahim Z, Hashimoto K, Quintini C, Kelly D, Vogt D, Eghtesad B, Fung J, Miller C, Tuthill R. Cruveilhier-Baumgarten disease in a patient with Turner syndrome: case report of a rare indication for liver transplantation. Liver Transpl 2008; 14:299302.doi:10.1002/lt.21374 PMid:18306332 